\title{
Correction to: Automatic identification of atypical clinical fMRI results
}

\author{
J. Martijn Jansma ${ }^{1,2} \cdot$ Geert-Jan Rutten $^{2} \cdot$ Lenny E. Ramsey $^{3}$ - T. J. Snijders ${ }^{1} \cdot$ Alberto Bizzi $^{4} \cdot$ Katharina Rosengarth $^{5}$. \\ Frank Dodoo-Schittko ${ }^{6} \cdot$ Elke Hattingen $^{7} \cdot$ Mar Jiménez de la Peña ${ }^{8} \cdot$ Gord von Campe $^{9} \cdot$ Margit Jehna $^{10}$. \\ Nick F. Ramsey ${ }^{1,11}$
}

Published online: 28 September 2020

(C) Springer-Verlag GmbH Germany, part of Springer Nature 2020

\section{Correction to: Neuroradiology (2020) https://doi.org/10.1007/s00234-020-02510-z}

The above article was published online with an incorrect affiliation. The correct affiliation of author Alberto Bizzi is as follows: Neuroradiology Department, Fondazione IRCCS Istituto Neurologico Besta, Milan, Italy.

Publisher's note Springer Nature remains neutral with regard to jurisdictional claims in published maps and institutional affiliations.

The online version of the original article can be found at https://doi.org/ $10.1007 / \mathrm{s} 00234-020-02510-\mathrm{z}$

Nick F. Ramsey

n.f.ramsey@umcutrecht.nl

1 Brain Center, Department of Neurology \& Neurosurgery, University Medical Center Utrecht, Utrecht, The Netherlands

2 Department of Neurosurgery, Elisabeth-TweeSteden Hospital, Tilburg, The Netherlands

3 Department of Neurosurgery, McGovernMedical School, University of Texas Health Science Center, Houston, TX, USA

4 Neuroradiology Department, Fondazione IRCCS Istituto Neurologico Besta, Rozzano, Milan, Italy

5 Institute for Experimental Psychology, University of Regensburg, Regensburg, Germany
6 Medical Sociology, Institute for Epidemiology and Preventive Medicine, University of Regensburg, Regensburg, Germany

7 Institute of Neuroradiology, Goethe University, Frankfurt, Germany

8 Diagnostic Imaging Department, Hospital Universitario QuirónSalud, Madrid, Spain

9 Department of Neurosurgery, Medical University of Graz, Graz, Austria

10 Division of Neuroradiology, Vascular and Interventional Radiology, Medical University of Graz, Graz, Austria

11 Braincarta BV, Utrecht, The Netherlands 